\title{
Altered expression of Akt signaling pathway parameters in prostate needle biopsies derived from benign, adjacent and cancerous tissue
}

\author{
SANDRA WAALKES ${ }^{1 *}$, PERIKLES SIMON ${ }^{3 *}$, JÖRG HENNENLOTTER ${ }^{2}$, JUDITH KNAPP $^{2}$, HOSSEIN TEZVAL $^{1}$, \\ JÜRGEN SERTH ${ }^{1}$, ARNULF STENZL ${ }^{2}$, MARKUS A. KUCZYK ${ }^{1}$ and AXEL S. MERSEBURGER ${ }^{1}$ \\ ${ }^{1}$ Department of Urology, Hannover University Medical School, Hannover; ${ }^{2}$ Department of Urology, Eberhard Karls \\ University Tuebingen, Tuebingen; ${ }^{3}$ Department of Sport Medicine, Johannes Gutenberg University, Mainz, Germany
}

Received September 21, 2009; Accepted December 18, 2009

DOI: 10.3892/or_00000758

\begin{abstract}
PTEN, p-Akt and p27kip1 are known to be altered in prostate cancer. The aim of the present study was to determine the addition of molecular markers to a classical histopathological approach to enhance the sensitivity in detection of malignant or premalignant lesions within prostatic biopsies. Forty-two fine needle biopsies from malignant, tumor adjacent and benign areas were obtained from 14 patients scheduled for a prostatic biopsy. Biomarker expression was determined by immunohistochemistry and correlated to different localizations. We observed a reduction of Akt signaling proteins in cancer tissue compared to benign controls with significantly lower expression of $\mathrm{p} 27^{\mathrm{kip} 1}$ $(\mathrm{P}=0.0024)$, $\mathrm{PTEN}(\mathrm{P}=0.0045)$ and $\mathrm{p}-\mathrm{Akt}(\mathrm{P}=0.028)$. A pathologist histopathologically classified the tumor adjacent tissue obtained from areas distinctly apart from the primary tumor as benign in all cases. In these regions we observed an intermediate expression of Akt signaling proteins without significant difference in relation to the findings in the malignant samples. The expression of Akt signaling proteins is reduced in prostate cancer compared to normal prostate tissue. The intermediate expression of these proteins in tumor adjacent tissue warrants further investigations into the role of Akt signaling in the carcinogenesis and early detection of prostate cancer. There seems to be a marked difference between the molecular and histopathological characterization of prostate tissue. Molecular markers might further augment the histopathological diagnosis suggesting the need for earlier repeated prostate biopsy in case of microscopic malignancy.
\end{abstract}

Correspondence to: Dr Axel S. Merseburger, Department of Urology, Hannover University Medical School, 30625 Hannover, Germany

E-mail: merseburger.axel@mh-hannover.de

${ }^{*}$ Contributed equally

Key words: prostate cancer, needle biopsies, PTEN, p-Akt, p27 ${ }^{\text {kip1 }}$

\section{Introduction}

Patterns of diagnosis and treatment of prostate cancer have changed dramatically in the past years. Whereas the histopathological heterogeneity of prostate cancer is well-known (1-3), the molecular mechanisms of prostate carcinogenesis remain poorly understood. Disturbances of proliferation and apoptosis are fundamental events in early carcinogenesis and might be useful in characterizing tissue that is histologically normal but at high risk for neoplastic growth. Genetically altered but phenotypically normal looking cells in the vicinity of a cancer focus are referred to as field effects. Identification of these effects could play an essential role in research and clinical practice. In Western countries millions of prostate biopsies are performed annually with the great majority being negative for cancer. Benign prostatic tissue is sampled very commonly due to the lack of imaging tools that fail to detect the cancerous tissue. Therefore, biomarkers identifying high risk non-cancer tissue in prostate needle biopsies could be very useful for classifying patients with negative biopsies according to their need for close follow-up or early re-biopsy.

This study examined the expression of Akt pathway proteins PTEN, p-Akt and p27 $7^{\mathrm{kip} 1}$ in benign, adjacent benign and prostate cancer tissue in biopsy cores.

PTEN, p-Akt, p27kip1 are important check points of cell cycle control, tumor growth and differentiation in prostate cancer (4). The PTEN tumor suppressor gene is one of the most frequently deleted genes in various human cancers, including prostate cancer $(5,6)$. The main function of PTEN relies on its phosphatase activity and subsequent antagonism of the PI3K/Akt pathway $(7,8)$. Loss of PTEN function results in accumulation of PIP3 and activation of its downstream effectors, including Akt (9-11). As a serine/threonine protein kinase, Akt functions by phosphorylating key intermediate signaling molecules, leading to an increase in cell metabolism, cell growth and cell survival (12). Furthermore, Akt activation seems to be important for the progression of prostate cancer to an androgen-independent state (13). The p27 kip 1 protein regulates cell cycle progression from the G1-phase to S-phase by its inhibitory interaction with the cyclin E/cdk2 complex. Loss of 2 $^{\text {kip } 1}$ expression has been shown to be a negative 
prognostic marker in various carcinomas as well as in prostatic carcinoma (14). Low levels of p27kipl may be as much a result of CDKN1B alterations as of (15) PTEN loss, because its function is mediated by the Akt signaling pathway (16).

\section{Materials and methods}

Patients. The study included 14 patients subjected to prostate needle biopsies who had been diagnosed with prostate cancer between 2002 and 2006 at Tübingen University Hospital. The age range was 53-74 (median 64.5) years. The Ethics Committee of the institution approved the study. The proportion of tumor cells within the needle biopsy ranged from $<25 \%$ to $>75 \%$.

Procedures. Representative tissue biopsies from patients with prostate cancer were selected, for this purpose one tumor biopsy cylinder, one adjacent, but benign cylinder and one benign distant biopsy cylinder was chosen for the study. Thus, glass slides contained 42 samples including 14 benign, 14 'adjacent' benign and 14 primary tumor tissue samples. Expression of PTEN, p-Akt and p27 $7^{\mathrm{kip} 1}$ was determined by immunohistochemistry. The biopsy containing slides were deparaffinized, rehydrated and immersed in 3\% hydrogen peroxide solution to block endogenous peroxidase activity. Antigen retrieval was accomplished by microwave heating specimens in a 0.01 citrate buffer for $15 \mathrm{~min}$. Biomarker expression was immunohistochemically detected by commercially available antibodies (PTEN and p27kip1 monoclonal mouse, p-Akt polyclonal Cell Signaling Technology, Inc., Beverly, MA, USA). The optimal dilutions were: PTEN and p27kip1, 1:200; and p-Akt, 1:150. After $12 \mathrm{~h}$ of incubation (PTEN, $2 \mathrm{~h}$ ) the sections were washed in TBS and incubated with a secondary biotinylated antibody (Vectastatin Elite ABC Kit, Vecto Laboratories, Inc., Burlingame, CA, USA) for $60 \mathrm{~min}$. The DAB system (Vector) was used for visualization according to the manufacturer's instructions. Sections were briefly rinsed in tap water, counterstained with Mayer's hematoxylin solution and then mounted. For negative control, the primary antibody was replaced by non-immune serum. All biopsy staining were assessed by two independent investigators (A.S.M. and J.H.) in a blinded manner so that neither of them knew the origin of the biopsies. The staining reaction was classified according to a semi-quantitative IHC reference scale ranging from 0 to 3 as previously described (17-19).

Statistical analysis. Score values nested into the three respective groups benign, adjacent and tumor showed unequal variance. Score values were therefore dichotomized into high expression with a score $>8$ and low expression with a score value $<9$. A global Pearson Chi-square test was used to analyze the overall difference in the frequency of the dichotomized score values between groups. A significant global test with $\mathrm{P}<0.05$ was followed by a post-hoc analysis using the Pearson Chi-square test comparing each group with the other two groups. Post-hoc P-values were corrected for multiple comparisons using the Bonferroni-Holm correction.


B
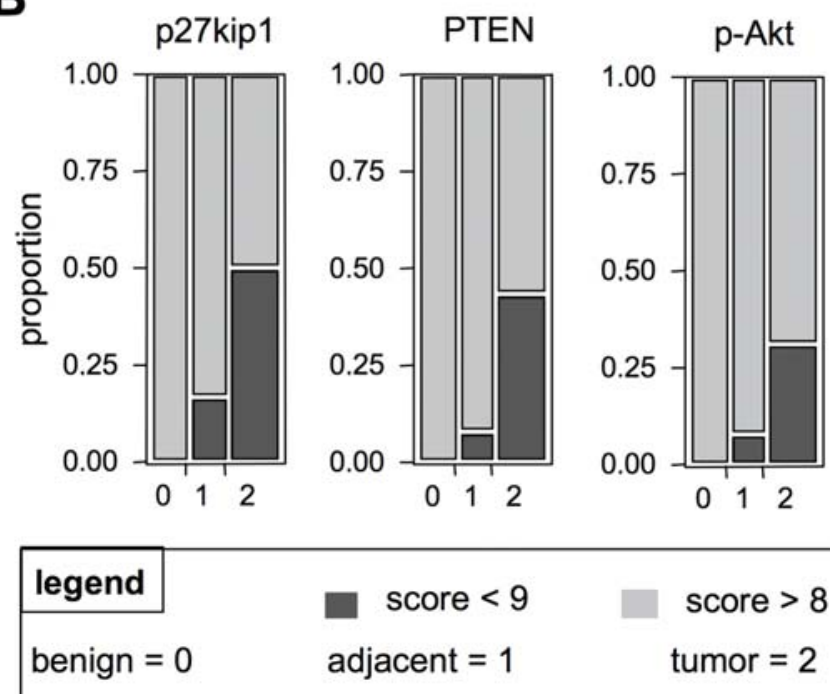

$$
\begin{array}{r}
\text { score }<9 \\
\text { adjacent }=1
\end{array}
$$

score $>8$

tumor $=2$

Figure 1. (A) Score values for the three different sample types belonging to each patient. Score values belonging to one patient are connected and presented in the same colour. (B) Mosaic plots for the frequency of high [(light grey) score $>8$ ] or low [(dark grey) score <9] expression within the three groups. Benign, 0 ; adjacent, 1 and tumor, 2.

\section{Results}

Fig. 1A shows the score values for the three different sample types belonging to each patient. Score values belonging to one patient are connected and presented in the same color. The score values nested into groups do not show equal variance. For all three different markers benign tissue samples do not reach score values $<9$. Fig. 1B shows mosaic plots for the frequency of high (score $>8$ ) or low (score $<9)$ expression within the three groups. For p27kip1 $\left(\mathrm{n}=40, \mathrm{x}^{2}=12.0, \mathrm{P}=0.0025\right)$, PTEN $\left(\mathrm{n}=41, \mathrm{x}^{2}=11.7, \mathrm{P}=0.0029\right)$ and $\mathrm{p}$-Akt $\left(\mathrm{n}=41, \mathrm{x}^{2}=7.4, \mathrm{P}=0.025\right)$ significant trends pointing at decreased frequencies of higher expression values of these tumor suppressors were found in the tumor tissue samples. Post-hoc analysis only showed significant differences for the benign tissue compared to the tumor tissue for $\mathrm{p}^{27^{\mathrm{kip} 1}}\left(\mathrm{n}=28, \mathrm{x}^{2}=11.3, \mathrm{P}=0.0024\right)$, PTEN $(\mathrm{n}=29$, $\left.\mathrm{x}^{2}=10.1, \mathrm{P}=0.0045\right)$ and $\mathrm{p}-\mathrm{Akt}\left(\mathrm{n}=29, \mathrm{x}^{2}=6.8, \mathrm{P}=0.028\right)$, but no differences for the adjacent group to the benign group for any of the markers. 


\section{Discussion}

As early stage prostate cancer is curable a timely diagnosis is essential. Furthermore, accurate detection of prostate cancer is critical for the appropriate management of patients. In most cases, a prostate biopsy is the initial means of making a diagnosis.

A major current problem in prostate cancer is to predict the behaviour of early and potentially localised disease (15). Some cases may remain dormant for many years without progressing, while others will progress rapidly. Therefore it is important to identify the patients who need to be treated and separate them from those who can be managed by active surveillance, for example in elderly or comorbid patients, thus sparing the latter of the adverse consequences of unnecessary treatment $(20,21)$. If tests are to be developed that will allow the prediction of clinical behaviour of patients diagnosed with prostate cancer, for example, following prostate-specific antigen (PSA) screening, it must be possible to perform the test on biological specimens obtained from the patients at the time of diagnosis, which would usually only include trans-rectal ultrasound (TRUS)-guided needle biopsy specimens, blood or urine.

Over the past several years we have appreciated that the utility of the needle cores goes well beyond the presence or absence of cancer. These needle cores also contribute to risk assessment in patients found to have cancer. Accurate grading is important to clinical decision-making. However, a general problem is that the main growth or expression pattern of the tumor tissue may not be present in the needle biopsy, especially in small tumors. This is mostly due to a lack of representative tumor areas in the biopsy, that can be caused by a very heterogeneous and clustered growth of prostate cancer throughout the gland (22).

To gain insight into the molecular mechanisms of carcinogenesis and tumor markers to predict a definitive prognosis and to find cellular functions suitable for therapeutic interference is the focus of many current investigations. Thus, more data are available on Akt expression in prostate cancer. The mechanism by which Akt signaling facilitates tumorigenesis and progression is multifactorial. However, inhibition of apoptosis and facilitation of cell cycle entry appear to be of great importance, as suggested by mounting evidence in prostate cancer and other malignancies. Loss of p2 $7^{\mathrm{kip} 1}$ protein expression in radical prostatectomy specimens has been shown to be an adverse prognostic factor in patients with clinically localized prostate cancer (14,23-27), and in those undergoing salvage prostatectomy after radiation therapy failure (28). In a previous study, we were able to demonstrate altered expression of p27kip1 in histologically benign tissue areas in whole mounted prostate cancer specimens (18). We concluded that, in adjacent benign tissue of whole prostate specimens, p-Akt and p27kip1 act similarly to that in cancerous tissue. These areas are part of the tumor mass, extending the histologically maligned region. In a study from 1999 our group postulated a significant correlation of decreased $\mathrm{p} 27^{\mathrm{kip} 1}$ expression with prostate cancer progression (29). Several studies confirmed these findings $(14,30)$. Because of this, loss of $\mathrm{p} 27^{\mathrm{kip} 1}$ has been suggested as a component of molecular staging $(27,31)$.
Whang et al (32) and Latini et al (33) postulated that PTEN alterations appear to be a late event, possibly influencing metastatic potential and progression to androgen independence rather than tumorigenesis. Moreover, PTEN mutations are more commonly found in metastatic compared to localized prostate cancers $(32,34-40)$. A role for PTEN mutations in resistance to chemotherapy is also proposed (41). Gene therapy approaches using transfected wild-type PTEN are being developed (42). PTEN clearly plays an important role in the progression of prostate cancer.

Despite the small number of patients in our study, this is the first study on these proteins and a possible alteration in benign tissue in prostate needle biopsies. Further investigation in Akt pathway will show its implication in the prognosis and therapy of prostate cancer and the possible diagnostic use in biopsy specimen. Further plans call for a multivariate model in a larger prospective study set comprised of various biomarkers and clinical variables to predict outcomes following negative biopsies.

\section{Acknowledgements}

Funding: Grant sponsor: Federal Ministry of Education and Research; Grant number: Fö 01KS9602; Grant sponsor: Fortune program; Grant number: F 1481010; Grant sponsor: Biomedical Science Exchange Program (BMEP).

\section{References}

1. Gleason DF: Histologic grading of prostate cancer: a perspective. Hum Pathol 23: 273-279, 1992.

2. Mostofi FK, Davis CJ Jr and Sesterhenn IA: Pathology of carcinoma of the prostate. Cancer 70: 235-253, 1992.

3. Mostofi FK, Sesterhenn IA and Davis CJ Jr: A pathologist's view of prostatic carcinoma. Cancer 71: 906-932, 1993.

4. Graff JR: Emerging targets in the AKT pathway for treatment of androgen-independent prostatic adenocarcinoma. Expert Opin Ther Targets 6: 103-113, 2002.

5. Hermans KG, van Alewijk DC, Veltman JA, van Weerden W, van Kessel AG and Trapman J: Loss of a small region around the PTEN locus is a major chromosome 10 alteration in prostate cancer xenografts and cell lines. Genes Chromosomes Cancer 39: $171-184,2004$

6. McMenamin ME, Soung P, Perera S, Kaplan I, Loda M and Sellers WR: Loss of PTEN expression in paraffin-embedded primary prostate cancer correlates with high Gleason score and advanced stage. Cancer Res 59: 4291-4296, 1999.

7. Vazquez F and Sellers WR: The PTEN tumor suppressor protein: an antagonist of phosphoinositide 3-kinase signaling. Biochim Biophys Acta 1470: M21-M35, 2000.

8. Vazquez F, Ramaswamy S, Nakamura N and Sellers WR: Phosphorylation of the PTEN tail regulates protein stability and function. Mol Cell Biol 20: 5010-5018, 2000.

9. Thomas GV, Horvath S, Smith BL, Crosby K, Lebel LA, Schrage M, Said J, De Kernion J, Reiter RE and Sawyers CL: Antibody-based profiling of the phosphoinositide 3-kinase pathway in clinical prostate cancer. Clin Cancer Res 10: 8351-8356, 2004.

10. Ramaswamy S, Nakamura N, Vazquez F, Batt DB, Perera S Roberts TM and Sellers WR: Regulation of G1 progression by the PTEN tumor suppressor protein is linked to inhibition of the phosphatidylinositol 3-kinase/Akt pathway. Proc Natl Acad Sci USA 96: 2110-2115, 1999.

11. Wu X, Senechal K, Neshat MS, Whang YE and Sawyers CL: The PTEN/MMAC1 tumor suppressor phosphatase functions as a negative regulator of the phosphoinositide 3-kinase/Akt pathway. Proc Natl Acad Sci USA 95: 15587-15591, 1998.

12. Dreher T, Zentgraf H, Abel U, Kappeler A, Michel MS, Bleyl U and Grobholz R: Reduction of PTEN and p27kip1 expression correlates with tumor grade in prostate cancer. Analysis in radical prostatectomy specimens and needle biopsies. Virchows Arch 444: 509-517, 2004. 
13. Murillo H, Huang H, Schmidt LJ, Smith DI and Tindall DJ: Role of PI3K signaling in survival and progression of $\mathrm{LNCaP}$ prostate cancer cells to the androgen refractory state. Endocrinology 142: 4795-4805, 2001.

14. Tsihlias J, Kapusta LR, DeBoer G, Morava-Protzner I, Zbieranowski I, Bhattacharya N, Catzavelos GC, Klotz LH and Slingerland JM: Loss of cyclin-dependent kinase inhibitor p27Kip1 is a novel prognostic factor in localized human prostate adenocarcinoma. Cancer Res 58: 542-548, 1998.

15. Yao SL and Lu-Yao G: Understanding and appreciating overdiagnosis in the PSA era. J Natl Cancer Inst 94: 958-960, 2002.

16. Graff JR, Konicek BW, McNulty AM, Wang Z, Houck K, Allen S, Paul JD, Hbaiu A, Goode RG, Sandusky GE, Vessella RL and Neubauer BL: Increased AKT activity contributes to prostate cancer progression by dramatically accelerating prostate tumor growth and diminishing p27Kip1 expression. J Biol Chem 275: 24500-24505, 2000

17. Theodorescu D, Broder SR, Boyd JC, Mills SE and Frierson HF Jr: Cathepsin D and chromogranin A as predictors of long term disease specific survival after radical prostatectomy for localized carcinoma of the prostate. Cancer 80: 2109-2119 1997

18. Merseburger AS, Hennenlotter J, Simon P, Muller CC, Kuhs U, Knuchel-Clarke R, Moul JW, Stenzl A and Kuczyk MA: Activation of the PKB/Akt pathway in histological benign prostatic tissue adjacent to the primary malignant lesions. Oncol Rep 16: 79-83, 2006.

19. Merseburger AS, Kramer MW, Hennenlotter J, Simon P, Knapp J, Hartmann JT, Stenzl A, Serth J and Kuczyk MA: Involvement of decreased Galectin-3 expression in the pathogenesis and progression of prostate cancer. Prostate 68: 72-77, 2008.

20. Dearnaley DP and Melia J: Early prostate cancer - to treat or not to treat? Lancet 349: 892-893, 1997.

21. Parker C: Active surveillance: towards a new paradigm in the management of early prostate cancer. Lancet Oncol 5: 101-106, 2004.

22. Mostofi FK: Grading of prostatic carcinoma. Cancer Chemother Rep 59: 111-117, 1975.

23. Thomas GV, Schrage MI, Rosenfelt L, Kim JH, Salur G, deKernion JB, Dorey F, Said J and Reiter RE: Preoperative prostate needle biopsy p27 correlates with subsequent radical prostatectomy p27, Gleason grade and pathological stage. J Urol 164: 1987-1991, 2000

24. Yang RM, Naitoh J, Murphy M, Wang HJ, Phillipson J, deKernion JB, Loda M and Reiter RE: Low p27 expression predicts poor disease-free survival in patients with prostate cancer. J Urol 159: 941-945, 1998.

25. Cordon-Cardo C, Koff A, Drobnjak M, Capodieci P, Osman I, Millard SS, Gaudin PB, Fazzari M, Zhang ZF, Massague J and Scher HI: Distinct altered patterns of p27KIP1 gene expression in benign prostatic hyperplasia and prostatic carcinoma. J Natl Cancer Inst 90: 1284-1291, 1998.

26. Cote RJ, Shi Y, Groshen S, Feng AC, Cordon-Cardo C, Skinner D and Lieskovosky G: Association of p27Kip1 levels with recurrence and survival in patients with stage $C$ prostate carcinoma. J Natl Cancer Inst 90: 916-920, 1998.

27. Vis AN, van Rhijn BW, Noordzij MA, Schroder FH and van der Kwast TH: Value of tissue markers p27(kip1), MIB-1, and CD44s for the pre-operative prediction of tumour features in screen-detected prostate cancer. J Pathol 197: 148-154, 2002.
28. Cheng L, Lloyd RV, Weaver AL, Pisansky TM, Cheville JC, Ramnani DM, Leibovich BC, Blute ML, Zincke $\mathrm{H}$ and Bostwick DG: The cell cycle inhibitors p21WAF1 and p27KIP1 are associated with survival in patients treated by salvage prostatectomy after radiation therapy. Clin Cancer Res 6: 1896-1899, 2000

29. Kuczyk M, Machtens S, Hradil K, Schubach J, Christian W, Knuchel R, Hartmann J, Bokemeyer C, Jonas U and Serth J: Predictive value of decreased $\mathrm{p} 27 \mathrm{Kip} 1$ protein expression for the recurrence-free and long-term survival of prostate cancer patients. Br J Cancer 81: 1052-1058, 1999.

30. Halvorsen OJ, Haukaas SA and Akslen LA. Combined loss of PTEN and p27 expression is associated with tumor cell proliferation by $\mathrm{Ki}-67$ and increased risk of recurrent disease in localized prostate cancer. Clin Cancer Res 9: 1474-1479, 2003.

31. Moul JW, Kane CJ and Malkowicz SB: The role of imaging studies and molecular markers for selecting candidates for radical prostatectomy. Urol Clin North Am 28: 459-472, 2001.

32. Whang YE, Wu X, Suzuki H, Reiter RE, Tran C, Vessella RL, Said JW, Isaacs WB and Sawyers CL: Inactivation of the tumor suppressor PTEN/MMAC1 in advanced human prostate cancer through loss of expression. Proc Natl Acad Sci USA 95: 5246-5250, 1998.

33. Latini JM, Rieger-Christ KM, Wang DS, Silverman ML, Libertino JA and Summerhayes IC: Loss of heterozygosity and microsatellite instability at chromosomal sites 1Q and 10Q in morphologically distinct regions of late stage prostate lesions. J Urol 166: 1931-1936, 2001.

34. Cairns P, Okami K, Halachmi S, Halachmi N, Esteller M, Herman JG, Jen J, Isaacs WB, Bova GS and Sidransky D: Frequent inactivation of PTEN/MMAC1 in primary prostate cancer. Cancer Res 57: 4997-5000, 1997.

35. Dong JT, Sipe TW, Hyytinen ER, Li CL, Heise C, McClintock DE, Grant CD, Chung LW and Frierson HF Jr: PTEN/MMAC1 is infrequently mutated in pT2 and pT3 carcinomas of the prostate. Oncogene 17: 1979-1982, 1998.

36. Feilotter HE, Nagai MA, Boag AH, Eng C and Mulligan LM: Analysis of PTEN and the 10q23 region in primary prostate carcinomas. Oncogene 16: 1743-1748, 1998.

37. Pesche S, Latil A, Muzeau F, Cussenot O, Fournier G, Longy M, Eng C and Lidereau R: PTEN/MMAC1/TEP1 involvement in primary prostate cancers. Oncogene 16: 2879-2883, 1998.

38. Suzuki H, Freije D, Nusskern DR, Okami K, Cairns P, Sidransky D, Isaacs WB and Bova GS: Interfocal heterogeneity of PTEN/MMAC1 gene alterations in multiple metastatic prostate cancer tissues. Cancer Res 58: 204-209, 1998.

39. Vlietstra RJ, van Alewijk DC, Hermans KG, van Steenbrugge GJ and Trapman J: Frequent inactivation of PTEN in prostate cancer cell lines and xenografts. Cancer Res 58: 2720-2723, 1998.

40. Wang SI, Parsons R and Ittmann M: Homozygous deletion of the PTEN tumor suppressor gene in a subset of prostate adenocarcinomas. Clin Cancer Res 4: 811-815, 1998.

41. Huang H, Cheville JC, Pan Y, Roche PC, Schmidt LJ and Tindall DJ: PTEN induces chemosensitivity in PTEN-mutated prostate cancer cells by suppression of Bcl-2 expression. J Biol Chem 276: 38830-38836, 2001.

42. Davies MA, Kim SJ, Parikh NU, Dong Z, Bucana CD and Gallick GE: Adenoviral-mediated expression of MMAC/PTEN inhibits proliferation and metastasis of human prostate cancer cells. Clin Cancer Res 8: 1904-1914, 2002. 